\title{
Assessment of bioelectrical activity of synergistic muscles during pelvic floor muscles activation in postmenopausal women with and without stress urinary incontinence: a preliminary observational study
}

This article was published in the following Dove Press journal:

Clinical Interventions in Aging

23 September 2015

Number of times this article has been viewed

Kuba Ptaszkowski,' Małgorzata Paprocka-Borowicz, ${ }^{2}$ Lucyna Słupska, ${ }^{2}$ Janusz Bartnicki, 1,3 Robert Dymarek, ${ }^{4}$ Joanna Rosińczuk, ${ }^{4}$ Jerzy Heimrath, ${ }^{5}$ Janusz Dembowski, ${ }^{6}$ Romuald Zdrojowy ${ }^{6}$

'Department of Obstetrics, ${ }^{2}$ Department of Clinical Biomechanics and Physiotherapy in Motor System Disorders, Wroclaw Medical University, Wroclaw, Poland; ${ }^{3}$ Department of Obstetrics and Gynecology, Health Center Bitterfeld/ Wolfen gGmbH, Bitterfeld-Wolfen, Germany; ${ }^{4}$ Department of Nervous System Diseases, ${ }^{5}$ Department of Gynaecology and Obstetrics, Faculty of Health Science, ${ }^{6}$ Department and Clinic of Urology, Faculty of Postgraduate Medical Training, Wroclaw Medical University, Wroclaw, Poland
Correspondence: Kuba Ptaszkowski Department of Obstetrics, Faculty of Health Science, Wroclaw Medical University, K Bartla 5, 5I-6I8

Wroclaw, Poland

Tel +48 7I 7841856

Email kptaszkowski@gmail.com
Objective: Muscles such as adductor magnus (AM), gluteus maximus (GM), rectus abdominis (RA), and abdominal external and internal oblique muscles are considered to play an important role in the treatment of stress urinary incontinence (SUI), and the relationship between contraction of these muscles and pelvic floor muscles (PFM) has been established in previous studies. Synergistic muscle activation intensifies a woman's ability to contract the PFM. In some cases, even for continent women, it is not possible to fully contract their PFM without involving the synergistic muscles. The primary aim of this study was to assess the surface electromyographic activity of synergistic muscles to PFM (SPFM) during resting and functional PFM activation in postmenopausal women with and without SUI.

Materials and methods: This study was a preliminary, prospective, cross-sectional observational study and included volunteers and patients who visited the Department and Clinic of Urology, University Hospital in Wroclaw, Poland. Forty-two patients participated in the study and were screened for eligibility criteria. Thirty participants satisfied the criteria and were categorized into two groups: women with SUI $(n=16)$ and continent women $(n=14)$. The bioelectrical activity of PFM and SPFM (AM, RA, GM) was recorded with a surface electromyographic instrument in a standing position during resting and functional PFM activity.

Results: Bioelectrical activity of RA was significantly higher in the incontinent group than in the continent group. These results concern the RA activity during resting and functional PFM activity. The results for other muscles showed no significant difference in bioelectrical activity between groups.

Conclusion: In women with SUI, during the isolated activation of PFM, an increased synergistic activity of RA muscle was observed; however, this activity was not observed in asymptomatic women. This may indicate the important accessory contribution of these muscles in the mechanism of continence.

Keywords: pelvic floor muscles, postmenopausal period, stress urinary incontinence, surface electromyography, synergistic muscle

\section{Introduction}

Stress urinary incontinence (SUI) is one of the most common types of urinary incontinence. SUI is defined as a complaint of involuntary loss of urine on effort or physical exertion or on sneezing, laughing, or coughing. ${ }^{1,2}$ SUI in most women is frequently caused due to hormonal changes during peri- and postmenopausal period or 
surgical procedures involving the pelvis. When SUI occurs in the postmenopausal period and is connected with hormonal disturbances, it probably leads to muscle and fascial flaccidity and decreased muscle tone. ${ }^{3-6}$ The risk factors for SUI include physical work, increased body mass index (BMI), and radiotherapy. ${ }^{3-7}$ If left untreated, urinary incontinence may cause serious psychological and social consequences such as depression, anxiety, low self-esteem, and social isolation. ${ }^{3,8-10}$ The pathogenesis of SUI is associated with anatomical abnormalities involving the urethra, urinary bladder, and urogenital diaphragm. Insufficiency of the urethral sphincter and vesicourethral ligament as well as weakening of the muscle-fascial structures of the whole pelvic floor impairs normal urinary continence. A direct cause of SUI is most likely the loss of support of the urinary bladder base, its triangle, and the proximal section of the urethra. In women with SUI, functional disorders of the urinary bladder and urethra as well as abnormal configuration of these structures have been demonstrated. ${ }^{1-3,7-13}$

Based on the International Urogynecological Association and International Continence Society, the evaluation of pelvic floor muscles (PFM) should be conducted using the following methods: by visual inspection, digital palpation, electromyography (EMG), dynamometer, perineometer, and ultrasound. ${ }^{14-22}$ Some studies show ${ }^{18,19}$ the possibility of using computed tomography or magnetic resonance imaging in the evaluation of the thickness, position, and the function of PFM during contraction.

The validity of the use of the surface EMG (sEMG) in the assessment of bioelectrical activity of PFM as well as muscles that act as synergistic muscles to PFM (SPFM) has been proven by many studies. ${ }^{20,23-27}$ It seems that sEMG is an objective, noninvasive, and safe method to assess the muscular activity of muscles included in this study. It could be interesting to check how the values of SPFM bioelectrical potentials correlate with the PFM activity during the functional tasks. According to literature, ${ }^{8,11,18,24,27-31}$ muscles considered to play an important role in the treatment of SUI are gluteus maximus (GM), adductor muscles (AM), rectus abdominis (RA), and abdominal external and internal oblique muscles, and the relationship between the contraction of these muscles and PFM activity has been established. Synergistic muscle activation intensifies a woman's ability to contract the PFM. In some cases, even for continent women, it is not possible to fully contract their PFM without involving the synergistic muscles. In addition, coactivation of abdominal and PFM plays a significant role in regulating internal abdominal pressure, which is also very important in proper continent function.
The primary aim of this study was to assess the sEMG activity of SPFM during resting and functional PFM activation in postmenopausal women with and without SUI. The secondary aim was to check the difference in PFM activation between incontinent and continent groups. We assumed that among the women with SUI, during the activation of PFM, the SPFM may exhibit greater activity to support the PFM, and as a consequence, they may play an important role in reducing the unintentional episodes of urine loss.

\section{Materials and methods Design}

The study was designed as a preliminary, prospective, crosssectional observational study to evaluate the sEMG activity of SPFM during resting and functional PFM activation in postmenopausal women with and without SUI.

\section{Participants}

Forty-two women with and without SUI were recruited from volunteers and patients visiting the Department and Clinic of Urology, University Hospital in Wroclaw, Poland. The study was approved by the Bioethics Committee of the Wroclaw Medical University (KB-611/2012), and was registered at the Australian New Zealand Clinical Trials Registry (ACTRN12613001144707). Written consent was obtained from all participants. The project was funded by the National Science Centre allocated on the basis of the decision number DEC-2011/03/N/NZ7/00505.

Study participants were recruited by convenience sampling and assigned to two groups: incontinent group (those with SUI) and continent group (healthy individuals).

Participants of the incontinent group were included if they had a history of SUI for more than 12 months before the study. Symptoms of SUI were evaluated by the International Consultation on Incontinence Questionnaire-Short Form (ICIQ-SF). The ICIQ-SF score of 5 or less on the day of the test or the presence of symptoms other than leaks when coughing or sneezing, leaks when physically active/exercising, and leaks when lifting heavy objects was taken as a further exclusion criterion. In addition, all the recruited patients in the postmenopausal stage attained menopause naturally, and none of them had undergone hysterectomy.

Participants of the continent group (control group) were closely matched for age, sex, weight, height, and BMI with the SUI patients. Criteria for participation in the control group differed from that of the incontinence group only with respect to having a negative history for SUI. 
Exclusion criteria for all the participants were inability to contract the PFM; had a previous history of gynecological and abdominal surgery; had a neurologic condition; had contraindications to measurements such as infection, menstruation, and allergy to nickel; or had other symptoms of female pelvic floor dysfunction.

\section{Experimental protocol and outcomes}

Bioelectrical activity of PFM and SPFM (AM, lower RA, and GM) was recorded using a surface electromyographic instrument in a standing position during resting and functional PFM activity (primary outcome). Before the measurements were taken, a physiotherapist taught the patients how to perform a correct PFM contraction. Some preliminary contractions were elicited to check if the probe was placed in an appropriate location and whether the contraction was performed properly. In standing position, the participants made five, 5-second long maximal isolated contractions of PFM (functional sEMG activity) with a 5-second long rest (resting sEMG activity) between each contraction. During these contractions, electrical activity was bilaterally recorded from the muscles AM, RA, and GM.

Electromyographic measurements were conducted using MyoSystem 1400L (Noraxon, Scottsdale, AZ, USA), with 8 sEMG channels. Technical specifications were as follows: common mode rejection ratio, minimum $100 \mathrm{~dB}$ at $50-60 \mathrm{~Hz}$; analog output gain, $\times 1,000$ standard (5,000 selected units); input impedance, $>100 \mathrm{M} \Omega$ on sEMG channels (isolated to $>3,000 \mathrm{~V}$ ); outputs, analog $\pm 5 \mathrm{~V}$ for all sEMG channels, digital 12-bit resolution per channel from USB port; inputs, 8 sEMG channels at $\pm 10 \mathrm{mV}$ maximum, 8 sensor channels at \pm 5 $\mathrm{V}$ maximum, power 100-240 VAC at 50/60 Hz (0.9 A maximum); sEMG amplifier performance, $1 \mu \mathrm{V}$ sensitivity, $<1 \mu \mathrm{V}$ RMS (root mean square) baseline noise; data acquisition, 12-bit resolution 8 channels, USB update to PC every millisecond; high-pass cutoff, $10 \mathrm{~Hz}$ first order on sEMG channels; low-pass cutoff, selectable 500 or $1,000 \mathrm{~Hz}$ on sEMG channels.

sEMG recordings were analyzed using Noraxon MyoResearch XP Master Edition version 1.07 software (Noraxon). Electromyographic data were bandpass filtered between 50 and $1,000 \mathrm{~Hz}$ (using finite impulse response filter), rectified, and smoothed using $50 \mathrm{~ms}$ RMS and were expressed in microvolts $(\mu \mathrm{V})$. Moreover, the sEMG data were normalized to the maximum RMS EMG amplitude recorded for PFM across a series of maximal contractions.

To record sEMG signals from the PFM, a Life-care Vaginal Probe PR-02 (Everyway Medical Instruments Co., Ltd., Taipei, Taiwan) was used. The pear-shaped probe had a total length of $7.6 \mathrm{~cm}$ and a maximal circumference of $2.8 \mathrm{~cm}$. The length of the recording plate was $4.5 \mathrm{~cm}$ and the active surface area was $7.68 \mathrm{~cm}^{2}$ per band. This probe was inserted up to the handle at the introitus of the vagina. ${ }^{31,32}$

The single-use hypoallergenic electrodes are disposable, self-adhesive $\mathrm{Ag} / \mathrm{AgCl}$ snap electrodes that have application only in sEMG analysis. Diameter of the circular adhesive area was $3.8 \mathrm{~cm}$ and that of the circular conductive area was $1 \mathrm{~cm}$. The interelectrode spacing between the recording electrodes was $2 \mathrm{~cm}$. The skin was prepared by shaving excess hair and wiping the skin with alcohol (Skinsept ${ }^{\mathbb{}}$ Pur, Ecolab, Krakow, Poland) to reduce impedance. ${ }^{20,31,33-35}$

The electrodes were placed parallel to the orientation of the muscle fibers of the following muscles: AM - the electrode was positioned midway between the posterior edge of the gracilis and the longitudinal fascial plane between the AM and the medial hamstrings; ${ }^{31,33} \mathrm{RA}$ - the electrodes were below the umbilicus, on the lower RA; $;^{31,34,35} \mathrm{GM}$ - the electrodes were placed at $50 \%$ on the line between the sacral vertebrae and the greater trochanter. ${ }^{31,36}$ The monopolar, reference electrode was placed on the anterior superior iliac spine.

\section{Statistical analysis}

Data were analyzed with Statistica 12 (Stat Soft Inc., Tulsa, OK, USA). For all variables, the mean, minimum and maximum values, and standard deviation (SD) were calculated. Shapiro-Wilk test was performed to assess the normality of distribution for the tested variables $(P>0.05)$. Differences in the bioelectrical activity of all the muscles between the two groups were compared using the Mann-Whitney $U$-test. Statistical analysis was conducted at $95 \%$ confidence interval and $P$-value less than 0.05 was considered statistically significant.

\section{Results}

Forty-two postmenopausal patients were screened for eligibility criteria. Thirty participants satisfied the criteria and were categorized into two groups: women with SUI $(n=16)$ and continent women $(n=14)$. Flow diagram including detailed information on the excluded participants is presented in Figure 1. Sixteen incontinent women (age: $\overline{\mathrm{x}}=63.9$ years, range: 50.0-75.0 years, SD: 5.9 years) and fourteen continent women (age: $\bar{x}=66.1$ years, range: $55.0-79.0$ years, SD: 6.3 years) were enrolled in this study. The groups were comparable in terms of age, weight, height, and BMI (Table 1).

Table 2 shows the comparison of sEMG activity of all the muscles during resting and functional PFM activity between the incontinent and the continent groups. Bioelectrical 


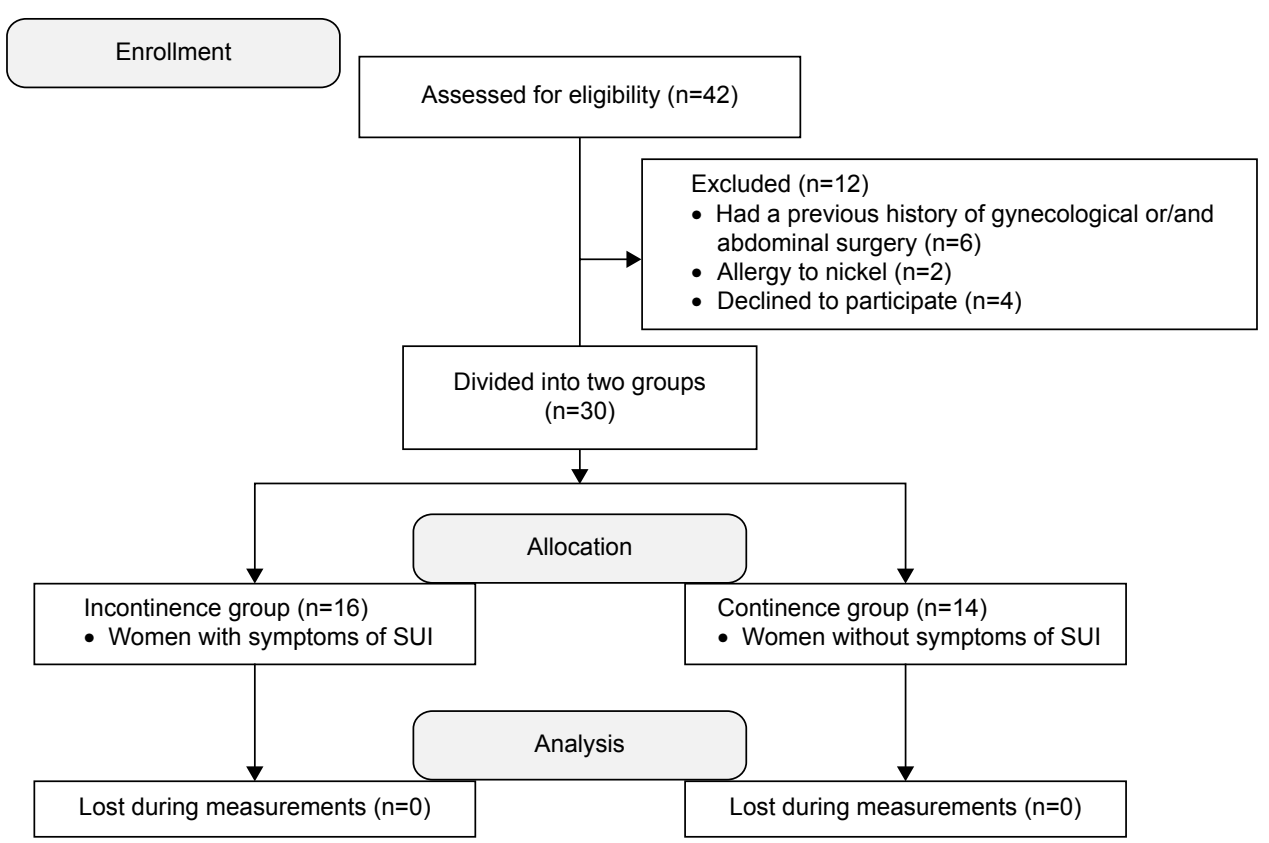

Figure I Flow diagram includes detailed information on the excluded participants. Abbreviation: SUI, stress urinary incontinence.

activity of RA was significantly higher in the incontinent group when compared to that in the continent group. These results concern the RA activity during resting and functional PFM activity. The results obtained for other muscles showed no significant difference in bioelectrical activity between the groups (Table 2).

There was no significant difference in normalized mean amplitude of EMG signal of PFM between women with and without SUI (Figure 2).

\section{Discussion}

In the present preliminary, prospective observational study, we assessed the sEMG activity of SPFM during resting and functional PFM activation in women with and without SUI in postmenopausal period. We also showed that there is a difference in the activation levels of PFM between incontinent and continent subjects. The study hypothesis was based on the assumption that women with SUI have greater activity of the SPFM during resting and functional PFM activation to support the PFM.

Incontinent women showed higher RA bioelectrical activity compared to that in the continent women. The data presented here is in agreement with those mentioned in the literature, ${ }^{27-31}$ demonstrating that symptoms of SUI can depend on the interaction between PFM and synergistic muscles such as abdominal, gluteal muscles, and the adductor muscles of the hip. Using sEMG, Thompson et $\mathrm{al}^{37}$ showed that the abdominal muscles were activated when a PFM contraction was performed. During PFM contraction, the symptomatic group showed lower levels of PFM activation and higher levels of abdominal and chest wall muscle activation when compared

Table I Demographic data of the women in each group

\begin{tabular}{|c|c|c|c|c|c|c|c|}
\hline & \multicolumn{3}{|c|}{$\begin{array}{l}\text { Incontinence group } \\
(n=16)\end{array}$} & \multicolumn{3}{|c|}{$\begin{array}{l}\text { Continence group } \\
(n=14)\end{array}$} & \multirow{2}{*}{$\begin{array}{l}\text { P-value } \\
\text { (Mann-Whitney } \\
\text { U-test) }\end{array}$} \\
\hline & Range & Mean & SD & Range & Mean & SD & \\
\hline Age (years) & $50.0-75.0$ & 63.9 & 5.9 & $55.0-79.0$ & 66.1 & 6.3 & 0.2246 \\
\hline Weight (kg) & $56.0-92.0$ & 70.1 & 10.5 & $52.0-86.0$ & 67.2 & 9.9 & 0.3423 \\
\hline Height (m) & $1.50-1.72$ & 1.62 & 0.06 & $|.46-1.7|$ & 1.59 & 0.07 & 0.2283 \\
\hline BMI $\left(\mathrm{kg} / \mathrm{m}^{2}\right)$ & $21.9-35.3$ & 26.7 & 3.7 & | $8.8-32.0$ & 24.9 & 3.5 & 0.1467 \\
\hline Number of pregnancies & $0.0-4.0$ & 1.6 & 1.0 & $0.0-3.0$ & 1.6 & 0.8 & 0.9944 \\
\hline ICIQ-SF & $5.1-16.0$ & 9.8 & 4.5 & - & - & - & - \\
\hline
\end{tabular}

Abbreviations: BMI, body mass index; ICIQ-SF, International Consultation on Incontinence Questionnaire-Short Form; SD, standard deviation. 
Table 2 Comparison of sEMG activity of muscles during resting and functional PFM activity $(\mu \mathrm{V})$ between incontinence and continence groups

\begin{tabular}{|c|c|c|c|c|c|c|}
\hline \multirow[t]{3}{*}{ Muscles } & \multicolumn{6}{|c|}{ Bioelectrical activity $(\mu \mathbf{V})$} \\
\hline & \multicolumn{3}{|c|}{ During resting PFM activity } & \multicolumn{3}{|c|}{ During functional PFM activity } \\
\hline & Incontinence group & Continence group & $P$-value & Incontinence group & Continence group & $P$-value \\
\hline \multicolumn{7}{|l|}{ Left side } \\
\hline AM & $4.1 \pm 1.2$ & $3.5 \pm 0.6$ & 0.0936 & $5.2 \pm 4.5$ & $4.3 \pm 1.8$ & 0.5726 \\
\hline RA & $5.8 \pm 1.0$ & $5.0 \pm 0.5$ & 0.0145 & $6.2 \pm 1.0$ & $5.1 \pm 0.4$ & 0.0017 \\
\hline GM & $3.3 \pm 0.6$ & $3.1 \pm 0.2$ & 0.7155 & $4.3 \pm 3.7$ & $3.5 \pm 0.8$ & 0.9612 \\
\hline \multicolumn{7}{|l|}{ Right side } \\
\hline AM & $3.9 \pm 1.0$ & $4.2 \pm 1.4$ & 0.4890 & $4.9 \pm 1.7$ & $4.9 \pm 1.4$ & 0.7821 \\
\hline RA & $6.1 \pm 2.3$ & $4.4 \pm 0.9$ & 0.0085 & $6.4 \pm 2.2$ & $4.6 \pm 1.0$ & 0.0037 \\
\hline GM & $3.8 \pm 1.8$ & $3.5 \pm 1.0$ & 0.8536 & $3.9 \pm 1.8$ & $4.5 \pm 1.9$ & 0.2304 \\
\hline
\end{tabular}

Note: Statistically significant values $(P<0.05)$ are marked in bold.

Abbreviations: PFM, pelvic floor muscle; sEMG, surface electromyography; AM, adductor magnus; GM, gluteus maximus; RA, rectus abdominis.

to the asymptomatic group. ${ }^{37}$ Similar conclusions were reported by Devreese et al..$^{38}$ The results of their study indicate that stress incontinence can be attributed to an imbalance between pelvic floor and lower abdominal muscle function. Moreover, the study by Arab et $\mathrm{al}^{8}$ confirmed the coactivation of pelvic floor and abdominal muscles during PFM contraction (measured by ultrasounds), although they did not find any difference between women with and without SUI.

Very often, the evaluation of the coactivation of the PFM and their synergists is presented in the context of the proper functional mechanism of these muscles in the population

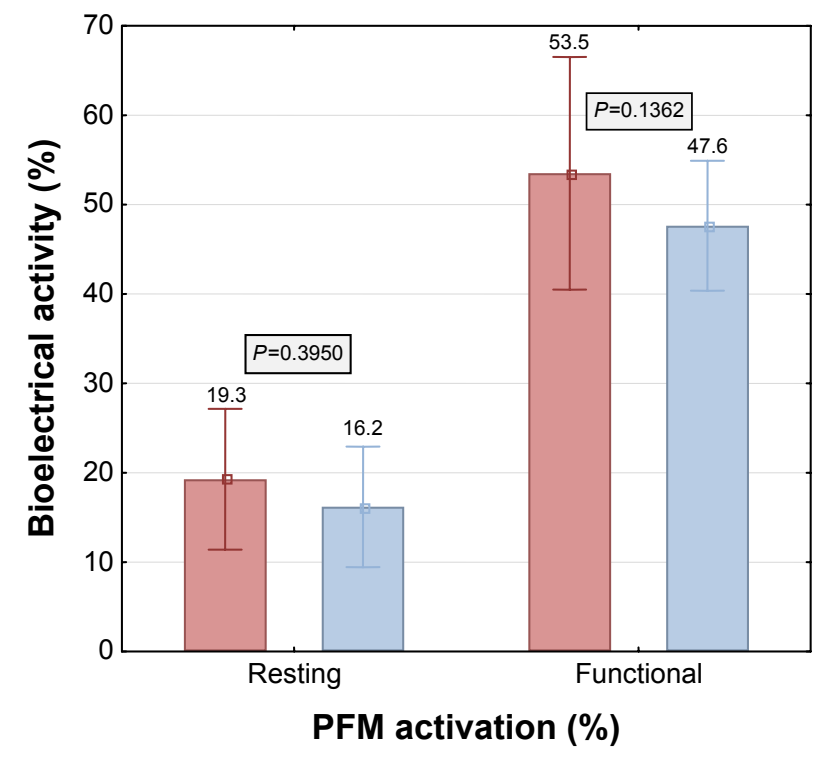

프 Incontinence group

Continence group

Figure 2 Comparison of resting and functional bioelectrical activity of the PFM between incontinence and continence groups.

Abbreviation: PFM, pelvic floor muscle. of healthy subjects. In healthy women, Junginger et al ${ }^{39}$ tried to examine the relationship between bladder neck displacement, electromyographic activity of the pelvic floor, abdominal muscles, and intraabdominal pressure. They concluded that in healthy females, there was co-contraction of the lower part of the transversus abdominis muscle and the PFM. Bladder neck elevation occurred only during PFM and the transversus abdominis contractions. ${ }^{39}$ In the studies conducted by Madill and McLean, ${ }^{22,29,30}$ researchers tried to define the relationships between the PFM and abdominal muscle activation and intravaginal pressure during PFM contractions in healthy women. The authors concluded that the abdominal muscles in continent women significantly affected the lower intravaginal pressure during voluntary PFM contractions. However, the intravaginal pressure was substantially reduced with increasing age. ${ }^{22}$ In addition, they also found defined patterns of abdominal muscle activity (among RA, transversus abdominis, and internal oblique muscles) in response to voluntary PFM contractions. ${ }^{29,30}$ The study by Neumann and Gill ${ }^{40}$ indicated that the transversus abdominis and the internal oblique muscles were recruited during all the PFM contractions. The authors even suggested that an effective contraction of the PFM was not possible during the relaxation of deep abdominal muscles. ${ }^{40}$ This statement is also confirmed by the data reported by Sapsford, ${ }^{41}$ in which voluntary activity in the abdominal muscles resulted in increased PFM activity. This suggests that advice to keep the abdominal muscles relaxed when performing pelvic floor exercises is incorrect and may adversely affect the performance of these exercises. ${ }^{41}$ However, it must be stressed that the last two studies ${ }^{40,41}$ were conducted on small number of participants.

In this study, the data recorded from other muscles (GM, AM) showed no significant difference in bioelectrical activity 
between the groups. Halski et $\mathrm{al}^{31}$ assessed the activity of muscles that act synergistically to PFM (RA, GM, AM, and left external oblique [EO]) during PFM contraction and relaxation in different orientations of the pelvis in women with SUI. They observed a higher activity of GM (left side) and RA (both sides) when the position of the pelvis was backward, which did not affect the sEMG activity of the PFM. It seems that SPFM may also play an important role in maintaining continence; however, further studies are needed to broaden our understanding of how the PFM work in conjunction with the synergistic muscles. ${ }^{31}$

In the literature, ${ }^{8-12,42}$ most of the studies underline the essential role of PFM in maintaining urinary continence. Amaro et $\mathrm{al}^{42}$ studied the function of PFM in incontinent and continent groups and confirmed the importance of functional and objective evaluation of PFM strength in assessing SUI, using both subjective control methods - like the urinary stream interruption test, visual survey of perineal muscle contractions, and transvaginal digital palpation - and objective evaluation, that is, by perineometer.

In this study, there was no difference in the bioelectrical activity of PFM between the incontinent and continent groups during the standing examination. However, Aukee et $\mathrm{al}^{9}$ reported different results when comparing the electrical activity of PFM of stress incontinent patients with that of asymptomatic control subjects. Their results showed that sEMG activity in 5-second pelvic floor contractions was lower in SUI patients than in healthy volunteers, when the subjects were in the standing position, but they did not find statistically significant difference when the subjects were in supine position. ${ }^{9}$ The differences between the results of this study and Aukee et al's study may be due to the reason that they presented sEMG results in microvolts. To avoid such user-dependent differences when comparing EMG data, a normalization method should be applied. Thompson et $\mathrm{al}^{37}$ have shown that during PFM contraction, the PFM were less active and the abdominal and chest wall muscles were more active in the symptomatic group, which partly coincides with the results obtained in this study. It is suggested that future studies, besides conventional ways of the use of the EMG, should also include new approaches of electromyographic assessment. Thereupon, an interesting study presented by Devreese et $\mathrm{al}^{38}$ showed that the investigation of the contraction sequence of superficial versus deep pelvic muscles may contribute to better understanding and explanation of incontinence. They found that the contraction sequence of muscles was consistent in continent but not in incontinent women. ${ }^{38}$

\section{Practical implications of the study}

Attention should also be given to the practical implications of this study. Since the activation of the abdominal muscles may contribute to the generation of PFM contraction, and consequently may contribute to the continence mechanism in postmenopausal women, a rehabilitation program including abdominal muscle training can be useful in treating this condition. Coactivation of abdominal muscle and PFM could be helpful in women who are not able to contract their PFM, and it may contribute to the strengthening of the PFM by activating the abdominal muscles during therapeutic sessions.

\section{Limitation of the study}

However, we acknowledge several important limitations. One of the limitations of this study is the sample size, which was limited to a relatively small group of patients. We included only those subjects who had SUI in order to assess the correlations in the homogenous population. Another area of concern in our study is that the patients were not diagnosed by urodynamics, and the type of incontinence was assessed using a urinary symptoms questionnaire. The lack of objective measurement of PFM strength by measuring vaginal squeeze pressure by perineometer or digital palpation testing between groups is another limitation of this study.

\section{Conclusion}

In postmenopausal women with SUI, during the isolated activation of PFM, an increased synergistic activity of RA muscle was observed. Such activity was not noticed in asymptomatic women. These results may indicate that women with SUI may intuitively use these muscles to compensate for urethral sphincter. This study also shows that abdominal muscles possess important accessory functions that help in maintaining the continence.

In further studies, it is important to take into account the assessment of the activities of other abdominal muscles together with the evaluation of treatment focused on abdominal muscles mentioned in this study in women with symptoms of SUI.

\section{Acknowledgment}

The project was funded by the National Science Centre allocated on the basis of the decision number DEC-2011/03/N/ NZ7/00505.

\section{Disclosure}

The authors report no conflicts of interest in this work. 


\section{References}

1. Abrams P, Cardozo L, Fall M, et al. The standardisation of terminology of lower urinary tract function: report from the Standardisation Sub-committee of the International Continence Society. Am J Obstet Gynecol. 2002;187(1):116-126.

2. Haylen BT, de Ridder D, Freeman RM, et al. An International Urogynecological Association (IUGA)/International Continence Society (ICS) joint report on the terminology for female pelvic floor dysfunction. Int Urogynecol J. 2010;21(1):5-26.

3. Nygaard CC, Betschart C, Hafez AA, Lewis E, Chasiotis I, Doumouchtsis SK. Impact of menopausal status on the outcome of pelvic floor physiotherapy in women with urinary incontinence. Int Urogynecol J. 2013;24(12):2071-2076.

4. Chmielewska D, Kwaśna K, Piecha M, et al. Selected methods of conservative treatment of stress urinary incontinence: current views. Part 1. Menop Rev. 2012;16(4):260-268.

5. Kwasńa K, Chmielewska D, Piecha M, et al. Physiotherapy treatment of urinary stress incontinence in women. Part 2. Menop Rev. 2012;16(5): 372-375.

6. Gameiro MO, Moreira EC, Ferrari RS, Kawano PR, Padovani CR, Amaro JL. A comparative analysis of pelvic floor muscle strength in women with stress and urge urinary incontinence. Int Braz J Urol. 2012;38(5) 661-666.

7. Madill SJ, Harvey MA, McLean L. Women with SUI demonstrate motor control differences during voluntary pelvic floor muscle contractions. Int Urogynecol J Pelvic Floor Dysfunct. 2009;20(4):447-459.

8. Arab AM, Chehrehrazi M. The response of the abdominal muscles to pelvic floor muscle contraction in women with and without stress urinary incontinence using ultrasound imaging. Neurourol Urodyn. 2011;30(1): $117-120$.

9. Aukee P, Penttinen J, Airaksinen O. The effect of aging on the electromyographic activity of pelvic floor muscles. A comparative study among stress incontinent patients and asymptomatic women. Maturitas. 2003;44(4):253-257.

10. Bø K. Pelvic floor muscle strength and response to pelvic floor muscle training for stress urinary incontinence. Neurourol Urodyn. 2003;22(7): 654-658.

11. Hung HC, Hsiao SM, Chih SY, Lin HH, Tsauo JY. An alternative intervention for urinary incontinence: retraining diaphragmatic, deep abdominal and pelvic floor muscle coordinated function. Man Ther. 2010;15(3): 273-279.

12. McLean L, Varette K, Gentilcore-Saulnier E, Harvey MA, Baker K, Sauerbrei E. Pelvic floor muscle training in women with stress urinary incontinence causes hypertrophy of the urethral sphincters and reduces bladder neck mobility during coughing. Neurourol Urodyn. 2013;32(8):1096-1102.

13. Shafik A, El-Sibai O. Effect of pelvic floor muscle contraction on vesical and rectal function with identification of puborectalis-rectovesical inhibitory reflex and levator-rectovesical excitatory reflex. World $J$ Urol. 2001;19(4):278-284.

14. Rett MT, Simoes JA, Herrmann V, Pinto CL, Marques AA, Morais SS. Management of stress urinary incontinence with surface electromyography-assisted biofeedback in women of reproductive age. Phys Ther. 2007;87(2):136-142.

15. Auchincloss C, McLean L. Does the presence of a vaginal probe alter pelvic floor muscle activation in young, continent women? J Electromyogr Kinesiol. 2012;22(6):1003-1009.

16. Botelho S, Pereira LC, Marques J, et al. Is there correlation between electromyography and digital palpation as means of measuring pelvic floor muscle contractility in nulliparous, pregnant, and postpartum women? Neurourol Urodyn. 2013;32(5):420-423.

17. Bø K, Finckenhagen HB. Is there any difference in measurement of pelvic floor muscle strength in supine and standing position? Acta Obstet Gynecol Scand. 2003;82(12):1120-1124.

18. Bø K, Sherburn M, Allen T. Transabdominal ultrasound measurement of pelvic floor muscle activity when activated directly or via a transversus abdominis muscle contraction. Neurourol Urodyn. 2003;22(6):582-588.
19. Bø K, Lilleås F, Talseth T, Hedland H. Dynamic MRI of the pelvic floor muscles in an upright sitting position. Neurourol Urodyn. 2001;20(2): 167-174.

20. Enck P, Vodusek DB. Electromyography of pelvic floor muscles. J Electromyogr Kinesiol. 2006;16(6):568-577.

21. Peschers UM, Gingelmaier A, Jundt K, Leib B, Dimpfl T. Evaluation of pelvic floor muscle strength using four different techniques. Int Urogynecol J Pelvic Floor Dysfunct. 2001;12(1):27-30.

22. Madill SJ, McLean L. Intravaginal pressure generated during voluntary pelvic floor muscle contractions and during coughing: the effect of age and continence status. Neurourol Urodyn. 2010;29(3):437-442.

23. Sapsford RR, Richardson CA, Maher CF, Hodges PW. Pelvic floor muscle activity in different sitting postures in continent and incontinent women. Arch Phys Med Rehabil. 2008;89(9):1741-1747.

24. Sapsford RR, Hodges PW. The effect of abdominal and pelvic floor muscle activation on urine flow in women. Int Urogynecol J. 2012;23(9): $1225-1230$.

25. Chmielewska D, Stania M, Sobota G, et al. Impact of different body positions on bioelectrical activity of the pelvic floor muscles in nulliparous continent women. Biomed Res Int. 2015:doi:10.1155/2015/905897.

26. Deffieux X, Hubeaux K, Porcher R, Ismael SS, Raibaut P, Amarenco G. Pelvic floor muscle activity during coughing: altered pattern in women with stress urinary incontinence. Urology. 2007;70(3):443-447.

27. Tahan N, Arab AM, Vaseghi B, Khademi K. Electromyographic evaluation of abdominal-muscle function with and without concomitant pelvicfloor-muscle contraction. J Sport Rehabil. 2013;22(2):108-114.

28. Stuge B, Mørkved S, Dahl HH, Vøllestad N. Abdominal and pelvic floor muscle function in women with and without long lasting pelvic girdle pain. Man Ther. 2006;11(4):287-296.

29. Madill SJ, McLean L. Quantification of abdominal and pelvic floor muscle synergies in response to voluntary pelvic floor muscle contractions. J Electromyogr Kinesiol. 2008;18(6):955-964.

30. Madill SJ, McLean L. Relationship between abdominal and pelvic floor muscle activation and intravaginal pressure during pelvic floor muscle contractions in healthy continent women. Neurourol Urodyn. 2006; 25(7):722-730.

31. Halski T, Słupska L, Dymarek R, et al. Evaluation of bioelectrical activity of pelvic floor muscles and synergistic muscles depending on orientation of pelvis in menopausal women with symptoms of stress urinary incontinence: a preliminary observational study. Biomed Res Int. 2014 : doi:10.1155/2014/274938.

32. Halski T, Ptaszkowski K, Słupska L, Dymarek R. The evaluation of bioelectrical activity of pelvic floor muscles depending on probe location: a pilot study. Biomed Res Int. 2013:doi:10.1155/2013/238312.

33. Watanabe K, Katayama K, Ishida K, Akima H. Electromyographic analysis of hip adductor muscles during incremental fatiguing pedaling exercise. Eur J Appl Physiol. 2009;106(6):815-825.

34. Ng JKF, Richardson CA, Parnianpour M, Kippers V. EMG activity of trunk muscles and torque output during isometric axial rotation exertion: a comparison between back pain patients and matched controls. J Orthop Res. 2002;20(1):112-121.

35. Ng JKF, Kippers V, Richardson CA. Muscle fibre orientation of abdominal muscles and suggested surface EMG electrode positions. Electromyogr Clin Neurophysiol. 1998;38(1):51-58.

36. Lovella GA, Blanchb PB, Barnesc CJ. EMG of the hip adductor muscles in six clinical examination tests. Phys Ther Sport. 2012;13(3): $134-140$.

37. Thompson JA, O'Sullivan PB, Briffa NK, Neumann P. Assessment of voluntary pelvic floor muscle contraction in continent and incontinent women using transperineal ultrasound, manual muscle testing and vaginal squeeze pressure measurements. Int Urogynecol J Pelvic Floor Dysfunct. 2006;17(6):624-630.

38. Devreese A, Staes F, Janssens L, Penninckx F, Vereecken R, De Weerdt W. Incontinent women have altered pelvic floor muscle contraction patterns. J Urol. 2007;178(2):558-562.

39. Junginger B, Baessler K, Sapsford R, Hodges PW. Effect of abdominal and pelvic floor tasks on muscle activity, abdominal pressure and bladder neck. Int Urogynecol J. 2010;21(1):69-77. 
40. Neumann P, Gill V. Pelvic floor and abdominal muscle interaction: EMG activity and intra-abdominal pressure. Int Urogynecol J Pelvic Floor Dysfunct. 2002;13(2):125-132.

41. Sapsford RR, Hodges PW. Contraction of the pelvic floor muscles during abdominal maneuvers. Arch Phys Med Rehabil. 2001;82(8): 1081-1088.
42. Amaro JL, Moreira EC, De Oliveira Orsi Gameiro M, Padovani CR. Pelvic floor muscle evaluation in incontinent patients. Int Urogynecol J Pelvic Floor Dysfunct. 2005;16(5):352-354.

\section{Publish your work in this journal}

Clinical Interventions in Aging is an international, peer-reviewed journal focusing on evidence-based reports on the value or lack thereof of treatments intended to prevent or delay the onset of maladaptive correlates of aging in human beings. This journal is indexed on PubMed Central, MedLine,
CAS, Scopus and the Elsevier Bibliographic databases. The manuscript management system is completely online and includes a very quick and fair peer-review system, which is all easy to use. Visit http://www.dovepress. com/testimonials.php to read real quotes from published authors. 